\title{
Primary hemifacial spasm: a neurophysiological study
}

\author{
ANGEL ESTEBAN, ${ }^{*}$ PEDRO MOLINA-NEGRO $\dagger$ \\ From Section of Clinical Neurophysiology, Hospital Provincial de Madrid, Spain* and Section of Clinical \\ Neurophysiology and Functional Neurosurgery, Hôpital Notre-Dame de Montréal, Canada. $\dagger$
}

SUMMARY A series of 53 cases of primary hemifacial spasm have been evaluated by means of blink reflexes and their results compared with a normal control group. Reflex responses were obtained by percutaneous electrical stimulus of both the supraorbital nerve (trigemino-facial reflex), and the facial nerve at the stylo-mastoid region (facio-facial reflex). The R2 response was considered abnormal when its latency was shortened (hyperactivity) or delayed (hypoactivity). Thirty-six out of 53 cases with primary hemifacial spasm showed abnormal responses, with a combination of facial nerve impairment (delayed R2 in the facio-facial reflex) and trigeminalfacial hyperactivity ( shortened R2 in the trigemino-facial reflex). Five cases showed hyperactivity in both the trigemino-facial reflex and the facio-facial reflex reflexes. These results suggest a state of hyperexcitability, probably at the level of the facial nucleus, combined with a peripheral facial nerve involvement in a high proportion of patients with primary hemifacial spasm.

The physiopathology of primary hemifacial spasm is not fully understood. A peripheral origin is suggested by cases of infection, tumour and vascular lesions at the root of the facial nerve, ${ }^{1-5}$ and is supported by the favourable results obtained by intracranial facial neurolysis. ${ }^{6-8}$ This mechanism would depend on ephaptic interaction of nerve fibres at the level of the lesion. ${ }^{9-13}$ A central origin, causing facial neuron hyperexcitability, in both primary as well as postparalytic facial spasm, has been claimed for a long time $e^{14}$ is and also in recent publications. ${ }^{16-23}$

The present study concerns blink reflexes obtained by trigeminal and facial stimulation in a group of 53 patients with primary hemifacial spasm. Blink reflexes were abnormal in 36 cases, in the form of either trigemino-facial hyperactivity (19 cases) or facial nerve impairment ( 17 cases). Among the former, nine demonstrated both types of disorder. Based on these results it is suggested that primary hemifacial spasm is the consequence of central facial hyperexcitability combined with impaired afferent conduction in the facial nerve.

\section{Material and method}

Fifty-three patients with primary hemifacial spasm and 20

Address for reprint requests: Dr Angel Esteban, Section of Clinical Neurophysiology, Hospital Provincial. Cl Dr Esquerdo, 4628007 Madrid, Spain.

Received 17 July 1984 and in revised form 29 January 1985. Accepted 8 March 1985 normal controls were studied. The 53 cases of primary $\vec{D}$ hemifacial spasm were evaluated between 1975 and 1980.0 The diagnosis was based on the usual clinical criteria. ${ }^{24}$ Fourteen were men and 39 women. The mean age wasi 52.7 years (range 24 to 81 ) and the mean duration of the symptoms was 5.7 years (range 3.5 to 50 ). In 46 cases the abnormal contractions began in the lower eyelid. Radiolog $\Omega$ ical studies excluded an underlying macroscopic pathology? The group of 20 normal controls had a mean age of 45.3 years (range 16 to 68 ).

With the patient in the supine position, two subcutaneous monopolar needles were inserted in the common portion of $\mathrm{m}$ orbicularis oculi at the external orbital border and in $m$ orbicularis oris at the middle of the nasomalar fold. The studies were performed with a Grass electromyograph. A four-channel memory oscilloscope with variable persistence was used for the recording. Once the suitable image was selected, a polaroid camera was used to obtain a permanent record.

A blink reflex can be obtained following stimulation of cranial nerves other than the well-known trigemino-facial reflex. A facio-facial reflex was described by one of us (PMN) at the III International Symposium of Facial Nerve Surgery held in Zürich in 1976. ${ }^{25}$ The same reflex has been studied further in different pathologies, either peripheral ${ }^{26}$ or central. ${ }^{27}$ For the trigemino-facial reflex the cathode was located on the supraorbital nerve at its exit from the orbital squiggle and the anode on the forehead, at the furthest point away from the medical line. For the facio-facial reflex the cathode was applied near the stylomastoid foramen in front of the mastoid process and behind the ear lobe, with the anode in a relatively posterior-inferior position. A constant current stimulator was used to deliver monopolar square waves of $0.2 \mathrm{~ms}$ duration and intensity of approximately twice the threshold for each reflex. This was 
Table 1 Trigemino-facial and facio-facial reflexes and $M$ potential in primary hemifacial spasm (mean $\pm 1 S D)$

\begin{tabular}{|c|c|c|c|c|c|c|c|c|}
\hline & \multicolumn{5}{|c|}{ Trigemino-facial reflex } & \multicolumn{2}{|c|}{ Facio-facial reflex } & \multirow[b]{2}{*}{$M$} \\
\hline & \multirow{2}{*}{$\frac{R 1}{\text { Latency }}$} & \multicolumn{4}{|l|}{$R 2$} & \multicolumn{2}{|l|}{$R 2$} & \\
\hline & & Latency & Dif. Lat. & Amplitude & Duration & Latency & Dif. Lat. & Latency \\
\hline $\begin{array}{l}\text { Involved side } \\
\text { Uninvolved side } \\
\text { Normal controls }\end{array}$ & $\begin{array}{l}10 \cdot 3 \pm 1 \cdot 0 \\
10 \cdot 1 \pm 0 \cdot 8 \\
10 \cdot 4 \pm 0.5\end{array}$ & $\begin{array}{l}28.7 \pm 7.4 \dagger \\
31 \cdot 1 \pm 4.4 \\
31.4 \pm 2.3\end{array}$ & $\begin{array}{l}2 \cdot 4 \pm 4 \cdot 2 \dagger \\
0.5 \pm 4 \cdot 2^{*} \\
1 \cdot 2 \pm 1 \cdot 8\end{array}$ & $\begin{array}{l}0.5 \pm 0.5 \\
0.4 \pm 0.3 \\
0.5 \pm 0.3\end{array}$ & $\begin{array}{l}46.6 \pm 12.4 \dagger \\
40.4 \pm 10.6 \\
38.5 \pm 11.5\end{array}$ & $\begin{array}{l}33.7 \pm 8.3 \dagger \\
32 \cdot 3 \pm 7.4^{*} \\
28.7 \pm 2.5\end{array}$ & $\begin{array}{l}5 \cdot 4 \pm 5 \cdot 7 \dagger \\
1.9 \pm 4 \cdot 7^{*} \\
3 \cdot 9 \pm 2 \cdot 9\end{array}$ & $\begin{array}{l}2.5 \pm 0.4 \\
2.5 \pm 0.4 \\
2.6 \pm 0.4\end{array}$ \\
\hline
\end{tabular}

* $\mathrm{p}<0.05$, when compared with normal values.

$t \mathrm{p}<0.05$, when compared with uninvolved side and normal values.

Table 2 Trigemino-facial response in 19 cases of primary hemifacial spasm with latencies smaller than 26 ms (mean \pm $1 S D)$

\begin{tabular}{|c|c|c|c|c|}
\hline & Latency & Dif. Lat. & Amplitude & Duration \\
\hline $\begin{array}{l}\text { Involved side } \\
\text { Uninvolved side }\end{array}$ & $\begin{array}{l}20.7 \pm 1.7^{*}(1) \\
30.8 \pm 5.7\end{array}$ & $\begin{array}{r}6 \cdot 2 \pm 3 \cdot 9^{*}(2) \\
-1 \cdot 1 \pm 4 \cdot 7\end{array}$ & $\begin{array}{l}0.7 \pm 0.6^{*} \\
0.3 \pm 0.2\end{array}$ & $\begin{array}{l}55 \cdot 3 \pm 7 \cdot 4^{*}(3) \\
40.8 \pm 11.8\end{array}$ \\
\hline
\end{tabular}

* $\mathrm{p}<0.01$, when compared with uninvolved side.

(1) A 20 ms arbitrary value was taken when $R 1$ and $R 2$ responses were without interruption (14 cases).

2) Non evaluated when $R 1$ and $R 2$ responses were without interruption.

(3) 60 ms maximal value.

achieved more frequently with an intensity of $10-15 \mathrm{~mA}$ for the trigemino-facial reflex and around 30 for the faciofacial reflex. The stimulation intensity was maintained unchanged on both sides and its frequency was low and irregular, about one shock every five seconds to avoid habituation.

The direct motor potential (M) was obtained in $\mathrm{m}$. orbicularis oculi with a supramaximal stimulation of the facial nerve at the stylomastoid foramen exit. The responses were simultaneously recorded in both $\mathrm{m}$. orbicularis oculi and, in the last 23 cases, in orbicularis oris as well.

In each case a number of superimposed responses were photographed and the following parameters were assessed according to similar criteria previously described: ${ }^{28} 29$ (a) Latency of the ipsilateral early (R1) response of trigemino-facial reflex and late (R2) responses of the trigemino-facial reflex and facio-facial reflex. The latency of the $M$ potential was also analysed. (b) Differential latency between the late ipsilateral and contralateral responses to the stimulus in the trigemino-facial reflex and the facio-facial reflex. (c) Maximum amplitude from peak to peak of the R2 potential (trigemino-facial reflex) and (d) Maximum duration of $\mathrm{R} 2$ potential (trigemino-facial reflex).

It is important to avoid confusion between a reflex response and a spontaneous spasm. In cases with continuous spasm, it was necessary sometimes to wait more than 30 seconds between two stimuli since voluntary contraction of any facial muscle can provoke a spasm. The patient was asked to maintain the gaze slightly below the horizontal plane to avoid contraction of $m$. frontalis. Relaxation of the jaw also was important. The possibility of electrical synkinesis, manifested by the diffusion of the reflex responses to the $\mathrm{m}$. orbicularis oris and occasionally to the $\mathrm{m}$. frontalis, was evaluated in the last 23 cases of primary hemifacial spasm.

The electromyographical characteristics of the muscular activity were studied in $\mathrm{m}$. orbicularis oculi in all the patients and simultaneously in the orbicularis oris in the last cases of the series.

Statistical evaluation The mean value of the results was obtained by comparing the studied groups using Student's $t$ test. Only when $p$ was less than 0.05 was the difference considered significant.

\section{Results}

The electromyographical recordings did not show spontaneous denervation activity. The clonic facial contractions were accompanied by irregular activity approximately synchronous with the hemifacial musculature, which frequently led to sustained activity lasting a few seconds. In the interspasm periods, complete electrical silence could be obtained but, on many occasions, isolated activity was detected.

In the trigemino-facial reflex, the latency of R1 was normal in all cases. The latency of R2 was shortened, the differential latency was lengthened, and the duration was greater on the hemispasm side compared with the healthy side, and compared with the normal group values (table 1). These differences were accentuated in the group of 19 patients that showed either a R2 latency response of less than 26 ms (lower limit of the normal mean latency plus 2 standard deviations) or no separation at all between the R1 and R2 (table 2).

A particularly interesting phenomenon was the frequent anticipation of the $R 2$ response on the pathological side following trigeminal stimulation on the normal side (fig). In the whole group, this gave a mean differential latency value (as compared to the 
$T-F R$
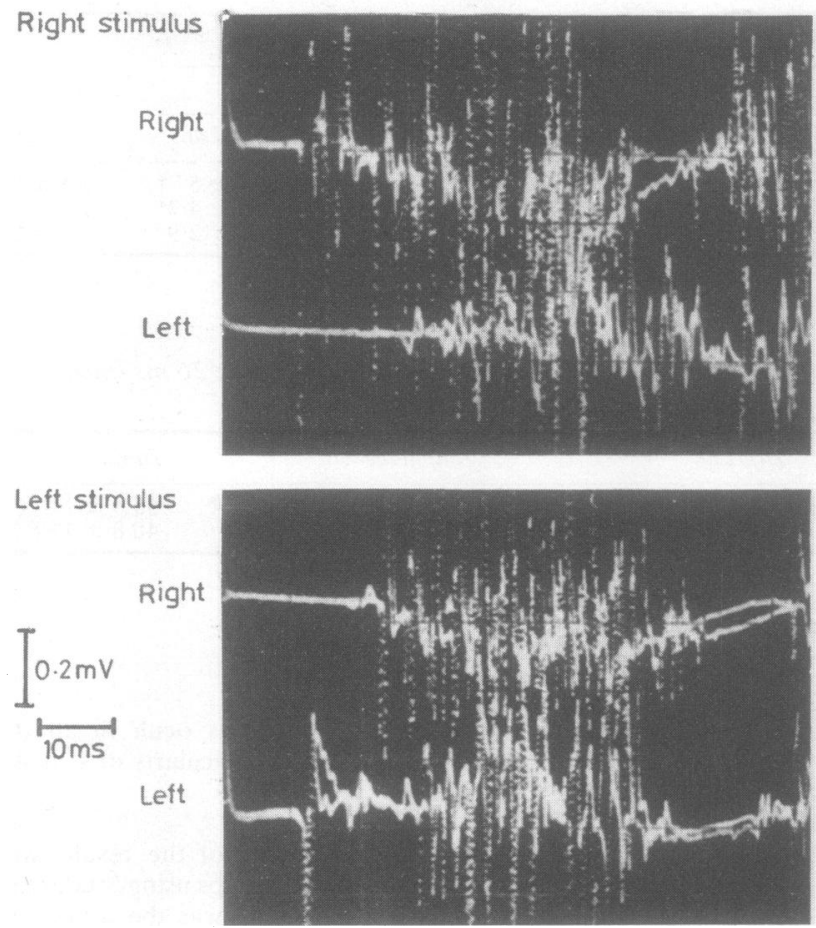

F-FR
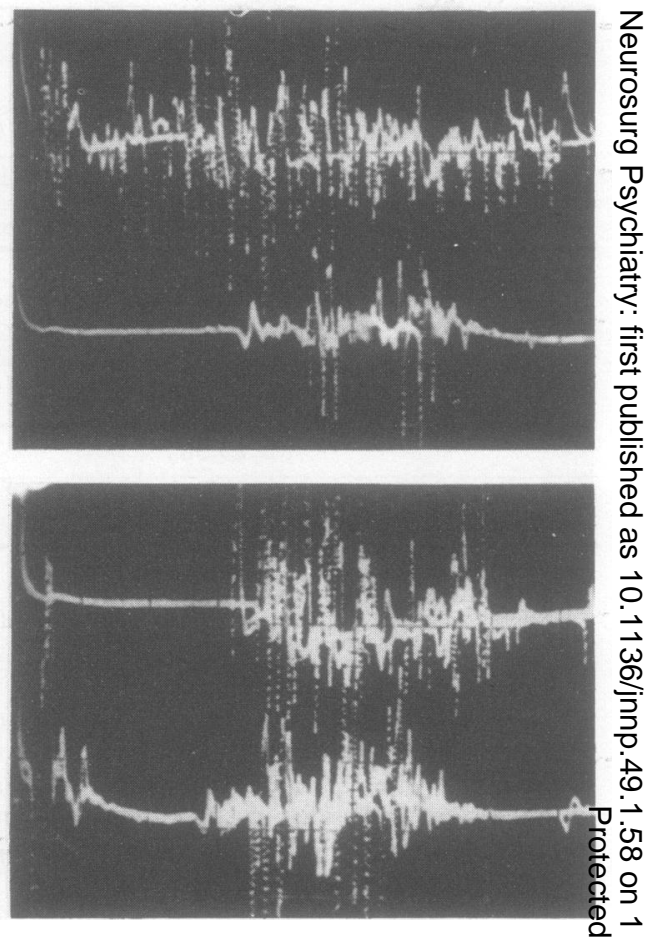

Fig. Right primary hemifacial spasm. With the ipsilateral trigeminal stimulus, $R 2$ response follows the $R 1$ potential withoug $\stackrel{C}{J}^{c}$ interruption (top, left). With the left stimulation, the $R 2$ response of the pathological side shows a systematic anticipation with respect to the normal stimulated side (bottom, left). On the right of the figure, facio-facial reflex. The R2 response follows the direct motor potential when the hemispasm side is stimulated (top). Each record with two superimposed traces $T-F R=$ trigemino-facial reflex; $F-F R=$ facio-facial reflex; $R=$ right side; $L=$ left side.

healthy side) which was less than normal ( $p<0.05)$, and which even produced a negative mean value in the latency subgroup in which the latencies were less than 26 ms (tables 1 and 2). In six cases the R2 latency was longer than $36 \mathrm{~ms}$ (normal mean plus 2 standard deviations).

The late response of the blink reflex, provoked by facial stimulation, did not show any difference in latency between the affected and the healthy sides. Both sides, nevertheless, showed a lengthening ( $\mathrm{p}<$ 0.05 ) with respect to the normal mean value (table 1). The latency of the $R 2$ response was greater than $34 \mathrm{~ms}$ (above the normal mean value plus 2 standard deviations) or it was not obtained on the pathological side in 27 of the 42 cases studied. In 13 cases, this finding was present on both sides. In contrast five cases showed an abnormally short latency and, at times, the response followed the direct motor potential without interruption (fig). Frequently, the differential latency could not be obtained from the pathological side because of the absence of con- tralateral response ( 15 out of 33 ) and its mean value showed an increase $(p<0.02)$ with respect to that obtained from the unaffected side (table 1 ).

Twenty of the last 23 cases in this series, studied since 1978 , showed a spread of the reflex responses to the $\mathrm{m}$. orbicularis oris and the $\mathrm{m}$. frontalis.

Classification of the blink reflexes in primary

hemifacial spasm (table 3).

Based on the results obtained by comparison between trigeminol-facial and facio-facial reflexes, a neurophysiological classification of primary hemifacial spasm is proposed. A group of 36 patients (group A) showed alterations in one or both reflexes. A hyperactive trigeminol-facial $\mathrm{R} 2$ response with a latency shorter than $26 \mathrm{~ms}$ was found in 19 cases (group A1). This was associated with a facio-facial reflex response which was also hyperactive (latency shorter than $20 \mathrm{~ms}$ ) on five occasions (group A1a); normal facio-facial reflex response occurred in $\sigma$ another five cases (group A1b), and a delayed $N$ 
Table 3 Blink reflexes in 53 cases of primary hemifacial spasm

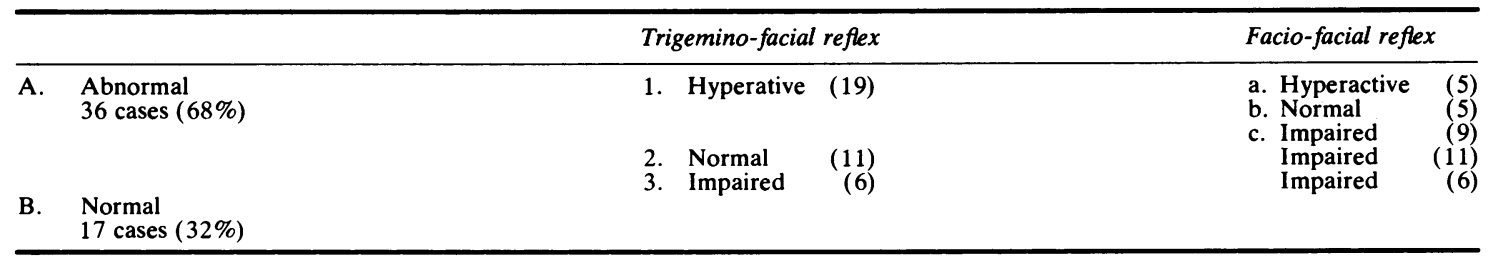

Number of cases within brackets.

response (latency longer than $34 \mathrm{~ms}$ ) or absence of potential in nine cases (group A1c). This same facio-facial reflex impairment was found to be associated with some normal trigemino-facial reflex in 11 cases (group A2) and with signs of lesions (latency of trigemino-facial reflex R2 longer than 36 $\mathrm{ms}$ ) in the remaining five cases (group A3).

In group $B$, the blink reflex responses were normal. In this group, nevertheless, 11 cases corresponded to the first of the series which were not evaluated with .respect to the facio-facial reflex. It was precisely this reflex in the remaining 42 cases which showed signs of lesion on 26 occasions $(62 \%)$, signs of hyperactivity on five occasions (12\%) and was normal on $11(26 \%)$.

\section{Discussion}

The results of previous studies on the blink reflexes in primary hemifacial spasm have been contradictory. Abnormally prolonged responses have been described ${ }^{30}$ as well as a premature response on the pathological side when stimulating the healthy one, ${ }^{31}$ and normal latencies with spread of the responses to the $\mathrm{m}$. orbicularis oris. ${ }^{32}{ }^{33}$ Besides the classical trigeminol-facial reflex, we included in our analysis of the primary hemifacial spasm the blink reflex obtained by facial nerve stimulation at the stylomastoid region. In this reflex both afferent and efferent branches belong solely or mainly to the facial nerve..$^{25-27} 3435$

In primary hemifacial spasm, differences were found between the affected and healthy sides and also in relation to the normal control group. The latency of the $\mathrm{R} 2$ response of the trigemino-facial reflex was shorter while the $R 2$ of the facio-facial reflex was delayed. These abnormalities were found in isolation or combined in 36 cases (group A), while 17 cases (group B) did not show such alterations. In group $A$, depending on the association of other changes in both reflexes, various subdivisions can be considered (table 3).

As in other studies, ${ }^{32}{ }^{33}$ synkinesias were found following electrical stimulation, with spread of reflex responses (trigemino-facial reflex and facio-facial reflex) to muscles which do not normally show them; in our cases, not only to $\mathrm{m}$. orbicularis oris but also to $\mathrm{m}$. frontalis. Their incidence was high, $(20$ cases from the 23 studied), and their presence, which can vary from one moment to the next in the same patient, ${ }^{33}$ probably represents the lowest level of facial hyperexcitability. In some of the cases in our series, such synkinesias were the only sign of trigeminal-facial hyperexcitability.

Many cases of primary hemifacial spasm have been described with various macroscopic pathological processes in the posterior fossa. ${ }^{235636}$ Such patients together with experience in the surgical treatment of primary hemifacial spasm by facial decompression in its petrous canal $^{10}$ and, more recently, by freeing the nerve from abnormal vessels in the ponto-cerebellar angle ${ }^{6-8}$ has given credence to the concept of ephaptic transmission at a compressive lesion in aetiology of hemispasm. ${ }^{1037}$ The facial synkinesis in primary hemifacial spasm has been similarly interpreted. ${ }^{33}$

From a clinical point of view, an ephaptic mechanism does not explain various aspects of primary hemifacial spasm: its onset and its almost regular predominance at the $\mathrm{m}$. orbicularis oculi, its circumscribed persistence in that muscle over a period of years, the influence of emotional tension on its intensity and, at times, on its provocation, and its occasional appearance during sleep. It is almost impossible to believe that such a topographically variable cause as an arterial loop in the pontocerebellar angle ${ }^{38}$ or an expansing process, systematically injures the same portion of facial nerve fibres (those supplying the $\mathrm{m}$. orbicularis oculi) as there is apparently no somatotopic arrangement of the facial nerve trunk. ${ }^{3940}$ The characteristics described in experimental ephaptic interaction, ${ }^{4142}$ such as the need for a prior stimulus for the pathological discharge, the exclusive transmission of motor fibres to sensory fibres, and the need for contact between adjacent damaged fibres, do not provide a satisfactory explanation of all the known clinical phenomena of primary hemifacial spasm. ${ }^{22}$

In 14 cases in our series in group A1, with signs of trigeminal-facial hyperexcitability (tables 2 and 3 ), 
the $\mathrm{R} 2$ potential followed the $\mathrm{R} 1$ potential without interruption. Also, in many of them the late response on the hemispasm side appeared before that of the unaffected one following stimulation of the latter (fig). If the first fact could be explained by a post-discharge of the early potential after the first activation wave arrived at the pathological nerve area, the second circumstance would necessarily require a prior level of hyperexcitability in the reflex arc, that is probably in the facial nucleus itself. This could explain the lower values of differential latency on the hemispasm side as compared with the healthy one (table 1).

We think that facial hemispasm, independent of its initial cause, should be considered a pathological increase of the blink reflex which, under normal conditions, is restricted to the $\mathrm{m}$. orbicularis oculi. $^{3343}$ However, Kugelberg ${ }^{44}$ has observed that, on certain occasions, a sufficiently strong stimulus or state of high emotional tension can cause the blink reflex in normal subjects to spread to other facial muscles. The progressive increase of facial nuclear excitability in hemispasm would cause a decrease in the reflex threshold, by any of its afferent roots. This would express itself initially as a localised and transitory contraction at the palpebral level, which would go on increasing in intensity and spread towards other facial territories. Gowers, ${ }^{14}$ who clearly anticipated this concept, explained that the usual onset of the hemispasm in $\mathrm{m}$. orbicularis oculi is due to the fact that "The motor mechanism of this muscle is more sensitive, in consequence of its energetic reflex action".

In our primary hemifacial spasm series it has been demonstrated that, together with the signs of trigeminal-facial hyperactivity, in some cases signs of a lesion coexist in facial conduction. The mechanism by which a facial peripheral lesion can reach the point of causing an increase in the excitability of its own nucleus is speculative at the present time. Experimental evidence suggests that an efferent fibre lesion ${ }^{4546}$ as well as deafferentation ${ }^{47}$ can give rise to secondary hyperexcitability of the corresponding motoneuronal pool, probably through an interneuronal reorganisation. We cannot exclude, however, the possibility that an afferent irritative mechanism exists as well. The reflex origin of primary hemifacial spasm elaborated by Hunt ${ }^{1}$ was supported by the observations of Rushworth, ${ }^{48}$ and was the theoretical basis of treatment by section of the $n$. intermedius. 6364950

The possibility of hyperexcitability of the facial neurons due to a lesion of afferent facial fibres is supported by the presence of bilateral delayed $R 2$ responses following stimulation of the facial nerve on the affected side in 25 cases of our series. A preliminary analysis of the anatomical findings during exploration of the cerebello-pontine angle and of the results of facial decompression from arterial, venous or arachnoidal structures, shows that those with obvious anatomical abnormalities and better results after surgery belong almost exclusively to this particular group.

\section{Addendum}

When this paper had been submitted to publication the works of Nielsen ${ }^{51}$ s2 about the pathophysiology of hemifacial spasm became known to us. In the affected side of 62 consecutive patients studied he found an increased latency of the R1 component of blink reflex with normal latency of R2 and a high amplitude on both responses. An afteractivity usually appeared after the $R 2$ potential and, sometimes, after $\mathrm{R} 1$. He unfortunately did not make simultaneous recording on both sides in order to measure the differential latency. These results persuade him to favour the theory of the ectopic excitation and ephaptic transmission in a facial nerve lesion although, as he states, "hyperexcitability of the facial nucleus could also play a role in the pathophysiology of hemifacial spasm".

\section{References}

1 Hunt JR. The sensory system of the facial nerve and its symp tomatology. J Nerv Ment Dis 1909;36:321-50.

${ }^{2}$ Revilla AG. Neurinomas of cerebellopontine recess: A clinicad study of one hundred and sixty cases including operative more tality and end results. Bull Johns Hopkins Hosp 1947;80: 254-96.

${ }^{3}$ Campbell E, Keedy C. Hemifacial spasm: a note on the etiology in two cases. $J$ Neurosurg 1947;4:342-7.

4 Thurel MR. Spasme facial périphérique. Neurochirurgie 1964; 10:104-10.

s Fabinyi GCA, Adams CBT. Hemifacial spasm: treatment by posterior fossa surgery. J Neurol Neurosurg Psychiatry 1978;41:829-33.

- Gardner WJ, Sava GA. Hemifacial spasm. A reversible pathophysiologic state. J Neurosurg 1962;19:240-7.

7 Jannetta PJ, Abassy M, Maroon JC, Ramos FM, Albin MS. Etiology and definitive microsurgical treatment of hemifacial spasm: Operative techniques and results in 47 patients. $J$ Neurosurg 1977;47:321-8.

${ }^{8}$ Loeser JD, Chen J. Hemifacial spasm: Treatment by microsurgical facial nerve decompression. Neurosurgery 1983;13:141-6.

' Bratzlavsky M, Vander Eecken H. Hemispasme facial primitif: corrélations cliniques et électromyographiques. Acta neurol belg 1977;77:365-82.

10 Woltman HW, Williams HL, Lambert EH. An attempt to relieve hemifacial spasm by neurolysis of the facial nerves: a report of two cases of hemifacial spasm with reflections on the nature of the spasms, the contracture and mass movement. Proc Staff Meet Mayo Clin 1951;26:236-40.

"Magun R, Esslen E. Electromyographic study of reinnervated muscles and of hemifacial spasm. Am J Phys Med 1959;38:79-86.

12 Gardner WJ. Concerning the mechanism of trigeminal neuralgia and hemifacial spasm. $J$ Neurosurg 1962;19:947-58. 
${ }_{13}$ Jesel M, Isch F. Hémispasme facial périphérique primitif. Etude electromyographique. Rev Neurol (Paris) 1964;110:181-8.

${ }^{14}$ Gowers WR. A Manual of Diseases of the Nervous System. Philadelphia: P. Blakistons, Son and Co., 1888, (cited in Ehni and Woltman ${ }^{24}$ ).

is Wartenberg R. Associated movements in the oculomotor and facial muscles. Arch Neurol Psychiatry 1946;55:439-88.

${ }^{16}$ Bratzlavsky M, Vander Eecken H. Postparalytic hemifacial spasm: pathogenetic problems. Electromoygraphy 1971; 11:75-81.

${ }^{17}$ Crue BL, Carregal EJA, Todd EM. Neuralgia. Consideration of central mechanism. Bull Los Angeles Neurol Soc 1964;29: 128-9.

${ }^{18}$ Cawthorn T. Clonic facial spasm. Arch Otolaryngol 1965;81:504-5.

19 Diamant H, Enfors B, Wiberg A. Facial spasm. With special reference to the chorda tympani function and operative treatment. Laryngoscope 1967;77:350-8.

${ }^{20} \mathrm{Hjorth} \mathrm{RJ}$, Willison RG. The electromyogram in facial myokimia and hemifacial spasm. J Neurol Sci 1973;20:117-26.

${ }^{21}$ Bratzlavsky M, Vander Eecken $H$. Altered synaptic organization in facial nucleus following facial nerve regeneration: An electrophysiological study in man. Ann Neurol 1977;2:71-3.

${ }^{22}$ Ferguson JH. Hemifacial spasm and the facial nucleus. Ann Neurol 1978;4:97-103.

${ }^{23}$ Martinelli P, Gabellini AS, Lugaresi E. Facial nucleus involvement in postparalytic hemifacial spasm? J Neurol Neurosurg Psychiatry 1983;46:586-7.

${ }^{24}$ Ehni G, Woltman HW. Hemifacial spasm. Review of one hundred and six cases. Arch Neurol Psychiat 1945;53:205-11.

${ }^{25}$ Molina P, Bertrand RA, Hardy J. The trigemino-facial reflexes. In: Fish U, ed. Facial Nerve Surgery. Amstelveen: Kugler Medical Publications 1977: 107-23.

${ }^{26}$ Molina P, Hardy J, Bertrand RA. Contribution of tregeminal and facial reflexes to the localization of Vth, VIIth and VIIIth cranial nerve dysfunction. Appl Neurophysiol 1978;41:15768.

${ }^{27}$ Molina-Negro P, Esteban A. Blinking reflexes and ischaemic lesions of the brain stem. In: Molina-Negro P, ed. Advances in Oto-laryngology. Basel: Karger, 1982:86-91.

${ }^{28}$ Esteban A, Gimenez-Roldan S. Blink reflex in Huntington's chorea and Parkinson's disease. Acta Neurol Scand 1975; 52: 145-57.

${ }^{24}$ Esteban A, Mateo D, Gimenez-Roldan S. Early detection of Huntington's disease. Blink reflex and levodopa load in presymtomatic and incipient subjects. J Neurol Neurosurg Psychiatry 1981;44:43-8.

${ }^{30}$ Caraceni T, Negri S. Le réflexe de clignement dans l' hemispasme facial primitif: considerations électromyographiques. Electromyography 1972;12:85-9.

${ }^{31}$ Smorto MP, Basmajian JV. Electrodiagnosis: A Handbook for Neurologists. Hagerstown: Harper and Row 1977: 138-42.
${ }^{32}$ Bohnert B, Stöhr M. Beitrag zum spasmus facialis. Arch Psyshiartr Nervenkr 1977;224:11-21.

${ }^{33}$ Auger RG. Hemifacial spasm: Clinical and electrophysiologic observations. Neurology (Minneap) 1979;29:1261-72.

${ }^{34}$ Willer JC, Lamour Y. Electrophysiological evidence for a faciofacial reflex in the facial muscles in man. Brain Res 1977; 119:459-64.

${ }^{35}$ Csécsei G. Facial afferent fibers in the blink reflex in man. Brain Res 1979;161:347-50.

${ }^{36}$ Maroon JC, Lunsford LD, Deed ZL. Hemifacial spasm due to aneurysmal compression of the facial nerve. Arch Neurol 1978;35: 545-6.

${ }^{37}$ Gardner WJ. Cross talk. The paradoxical transmission of a nerve impulse. Arch Neurol 1966;14:149-56.

${ }^{38}$ Ouaknine GE. Microsurgical anatomy of the arterial loops in the ponto-cerebellar angle and the internal acoustic meatus. In: Samii M, Jannetta PJ, eds. The Cranial Nerves. Heidelberg: Springer-Verlag, 1981:378-90.

34 Sunderland S, Cossar DF. The structure of the facial nerve. Anat $\operatorname{Rec} 1$ 1953; 116: 147-65.

${ }^{40}$ Esslen E. The Acute Facial Palsies. Berlin: Springer-Verlag, 1977:7-8.

${ }^{41}$ Granit R, Leksell L, Skoglund CR. Fibre interaction in injured or compressed region of nerve. Brain 1944;67:125-40.

${ }^{42}$ Kugelberg E. 'Injury activity' and 'trigger zones' in human nerves. Brain 1946;69:310-24.

${ }^{43}$ Kimura J, Rodnitzky RL, Okawara SH. Electrophysiologic analysis of aberrant regeneration after facial nerve paralysis. Neurology (Minneap) 1975;25:989-93.

${ }^{44}$ Kugelberg E. Facial reflexes. Brain 1952;75:385-96.

${ }^{45}$ Purves D. Functional and structural changes in mammalian sympathetic neurones following interruption of their axons. $J$ Physiol (Lond) 1975;252:429-63.

${ }^{46}$ Mendell LM, Munson JB, Scott JG. S Alterations of synapses on axotomized motoneurones. J Physiol (Lond) 1976; 255:67-79.

${ }^{47}$ Loeser JD, Ward AA. Some effects of deafferentation on neurons of the cat spinal cord. Arch Neurol 1967;17:629-36.

${ }^{48}$ Rushworth G. Spasm of skeletal muscle. In: Proceedings of a Symposium on Skeletal muscle spasm. Riker Laboratories, 1961:9-29. (Cited in Hjorth and Willison (20)).

${ }^{44}$ Crue BL, Todd EM, Carregal EJA. Compression of intracranial portion of facial nerve and section of nervus intermedius for hemifacial spasm. Bull Los Angeles Neurol Soc 1968;33:70-3.

so Neagoy DR, Dohn DF. Hemifacial spasm secondary to vascular compression of the facial nerve. Cleve Clin $Q$ 1974;41:20514.

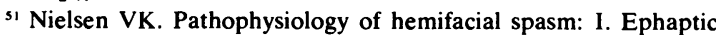
transmission and ectopic excitation. Neurology (NY) 1984;34:418-26.

52 Nielsen VK. Pathophysiology of hemifacial spasm: II. Latera spread of the supraorbital nerve reflex. Neurology (NY) 1984;34:427-31. 